\title{
Cardio Patients are Monitoring the Physical Activities to Reduce Mortality
}

\author{
A.Zechariah Jebakumar, R.Ravanan
}

\begin{abstract}
Aim - The general well-being, example of overcoming adversity of the primary portion of the twentieth century, at that point the decrease in mortality from coronary illness (CHD) and stroke has been the example of overcoming adversity of the century's most recent 4 decades [9]. Physical movement has been appeared to decrease mortality in a portion reaction design [6]. Current rules prescribe 500-1000 metabolic equal undertaking (MET) - min every seven day stretch of customary physical action. This investigation meant to think about the effect of recreating period body action on death in essential against optional cardiovascular counteraction [4].

Results and Methods: There was a backwards connection among the mortality and the body action level chance in the two gatherings. Advantage in the optional avoidance bunch remained demonstrated towards standpoint more noteworthy excluding such as the essential anticipation gathering [10]: each 500 METER in a week increment in body action brought about a 16\% and 9\% hazard decrease in mortality in the auxiliary and essential counteraction gatherings, individually (communication $P<0.003$ ). Moreover, while people without CVD profited the most somewhere in the range of 1 and 500 MET for seven day stretch of body activity [2], Advantage of persons through CVD preceded over 500 - 1000 MET in a week [11]. Balanced death, danger based on people by CVD, which played out an elevated equal of body movement ( $>1000$ MET in a week) remained demonstrated toward remain equivalent toward before lesser then which based on threw partners deprived of CVD [3].

Keywords: Coronary heart disease, cardiovascular mortality rate, Physical activity, Disparities, Hypertension.
\end{abstract}

\section{INTRODUCTION}

The Strong indication backing's, an invert partition response association among the mortality and the body activity. This Present rules, suggest at any rate 500 to 1000 diabolic proportional undertakings (MET) - minutes out of each seven day stretch of moderate-to-energetic physical action [2]. This can be tragically, considered has required indicated that not exactly $50 \%$ of grownups accomplished in this degree of physical movement, while $33 \%$ do not be a physical action by any stretch of the thoughts [12].

The current proof of the portion - reaction relationship is generally founded on sound individuals. While the people through circulatory illness (CVD) and remain on advanced hazard for death and dreariness. There was additionally willing in general to have stationary ways of life \& low body dynamic, that is persons deprived of CVD [2]. Mediation through exhaustive circulatory restoration programs must be remained and appeared towards the lessening cardiovascular death in an emergency through cardiac heart sickness.

Revised Manuscript Received on March 05, 2020.

* Correspondence Author

A.Zechariah Jebakumar*, Lecturer, Prince Sultan Military College of Health Sciences, Dhahran, Kingdome of Saudi Arabia. Email id: zechariah@psmchs.edu.sa.

Dr.R.Ravanan, Joint Director of Collegiate Education, Chennai. Email id: ravananstat@gmail.com

(C) The Authors. Published by Blue Eyes Intelligence Engineering and Sciences Publication (BEIESP). This is an open access article under the CC BY-NC-ND license (http://creativecommons.org/licenses/by-nc-nd/4.0/)
Though body action is by and large suggested for auxiliary CVD avoidance by contemporary rules, and there is yet a scarcity of information in regards to the connection among body action and death, and the explicitly between sick persons with previous CVD. Also, no past examinations have thought about the advantageous impact of physical movement between important versus optional CVD avoidance [9].

The surveyed among the population based associate new that examination through clarifying in what way the advantage of body movement connects through the nearness about CVD [4].

(I) It can be check the stages of body movement amongst participants without, also with Cardio.

(II) Distinguish between the connection amongst body action and death between sick people through CVD [1].

(III) Just think about the relationship amongst the essential \& auxiliary anticipation gatherings [6].

\section{LITERATURE REVIEW}

Hong-Lan Li, Yu-Tang Gao and $M$ Shafiur Rahman [2018] Researched the relationship of LTPA that total-reason and origin-explicit death between East Asian populations, with sound people and persons through standing constant maladies, which takes remained lower all around portrayed [4]. It can be realize that combine examinations between 526638 East Asian people selected in 9 planned accomplices remembered for the Asia Unit Grouping. Cox relative threats declines remained utilized to determine risk proportions (HRs) and 96\% certainty interims (CIs) related through LTPA in the wake of modifying for sex, age, training \& conjugal and smoking position [16]. No reasonable adjusting the impacts by sex, weightiness file or smoking status was documented. It had been rejected the subjects with missing information in regards to LTPA ( $\mathrm{n}=$ 33 329), age (1), fundamental status (44) and persons aimed at whom information on endurance remained worthless or gone (125), through a sum of $5.67 \%$ of education members, departure 578838 issues (324 846 men and 344885 ladies) aimed at the examination. The Singular information after partaking partners remained gathered also composed aimed at factual investigation [19].

Fulton JE, Ballard RM, George SM and Piercy KL [2018], The outline key rules in the Body Movement Rules for Americans, 2nd version (PAG) [8], of the panel to be tended to 38 inquiries and 104 subsections and it has reviewed the proof depends on the consistency and the nature of exploration. The Proof was evaluated as solid or death was the premise of strategic rules [5]. 
The Health and Human Services (HHS) division put together about the PAG with respect to the 2018 Body Movement Rules Optional Group Technical Explosion [7]. The Pregnant and baby blues ladies ought to do in any event among 150 minutes of moderate-power of oxygen consuming movement seven days. Grownups with constant conditions or inabilities, which are capable, ought to follow the key rules for grownups and do both oxygen consuming and muscle-fortifying exercises. Proposals stress that moving more and sitting less will profit about everybody [4].

People playing out the less physical action advantage most by even unobtrusive increments in moderate-to-vivacious physical movement [1]. Extra advantages will happens with increasingly physical action [20]. This Wellbeing experts and approach producers ought to encourage familiarity with the rules and advance to the medical advantages of physical action and bolster endeavours to actualize projects, practices, and arrangements to encourage expanded physical activity and to improve the strength of the US populace [21].

Harri Sievänen, Pauliina Husu, Kari Tokola and Tommi Vasankari [2018], the Researched contrasts inequitably estimated stationary conduct (SB) and body action (PA) stages in issues with cardio illness (CVD) determination or extraordinary CVD hazard contrasted and sound controls. The present investigation incorporates a sub-sample ( $n=2489$, Health 2018 examinees) of members, who went to well-being assessments and wore a trivial accelerator $(\geq 5$ days). Sick persons through CVD remained recognized and CVD hazard was determined from others utilizing the Framing-ham Risk Score (FRS). Members were ordered into gatherings: FRS $<21 \%$; FRS $=21 \%-41 \%$; FRS $>41 \% / C V D$. The Crude increasing speed information was examined with mean abundance deviation (MAD) and the plan on behalf of act estimate (APE). Distraught comparing to force of PA was changed over to the diabolic reciprocals (MET) and ordered to bright (2.6-3.8 METs) and death to vivacious PA (MVPA $\geq 4.1$ METs) [21]. Gorilla perceives SB and standup. Number and aggregated occasions of PA and SB sessions varied among the CVD hazard gatherings. The Causal study of the essential to evaluate the significance of $\mathrm{PA}$ and SB in the avoidance and restoration of CVDs [12]

\section{METHOD - STUDY OF RESEARCH \& DATA SOURCE}

The nationwide well-being catalogue, the Donthams Speciality Clinics, Pollachi SIDCO, Coimbatore region [4]. Insights concerning the companion have been portrayed already. Enrolls in the protection framework matured 40 years or more seasoned qualify for experience a general well-being screening program each 2 years [4]. The program incorporates self-report surveys, anthropocentric and circulatory strain estimates, and research centre tests utilizing blood and pee tests [9]. Institutionalized surveys are utilized to obtain data on past therapeutic history, family, ancestry, and method of life factors, for example, smoking, liquor consumption, and physical action. The valuation has become confined taken away a survey by using the Coimbatore District SIDCO Pollachi region Donthams Specialty Clinic. It agreed to the prerequisites of the Statement of holism, and the requirement for educated assent was postponed [3].
A sum of 552689 people who knowledgeable the transmission program somewhere in the range of 2009 and 2015 and finished studies on physical movement were removed from the associate. Every special case document is tested for an established order set apart by way of CVD from 2012 contemporary of the growing admission. Examine the object with earlier, more caudal localized necrosis (MI) [4], additional ischemic heart infections, constant cardiovascular breakdown (HF) or earlier stroke remained measured to need CVD (optional counteraction gathering) [15]. The essential Figure 1, expression the frequency pace of death for every 1000 man years flaky by the nearness of CVD and the degree of body movement [12].

\section{RESLTS AND DISCUSSION OF BODY MOVEMENT}

The degree of reduction period of body movement had remained the gathered through personality-explosion organized polls utilizing a week review technique [17]. Study comprised 4 inquiries that tended to the standard recurrence (existences out of each seven day stretch) [9].

(I) Light-power action for any event $30 \mathrm{~min}$ (for example strolling on a measured and also comfortable stride) [10].

(ii) Proper-effort motion for every half an hour (as a model active walking, gradual biking, or tens duplication) [11].

(iii) Enthusiastic force movement for in any event $20 \mathrm{~min}$ (for sample bicycling or running $>21 \mathrm{~km} / \mathrm{h}$, ascending energetically active a slope, or taking an interest in a heart stimulating exercise class) [16]. Evaluations of 3.1, 4.4, and 8.1 METs were doled out for normal-force, death-power, and overwhelming force exercises, individually [24]. Body maintenance associated purpose utilization (MET 7 days) turned into limited with the aid of which includes the eventual outcome of reuse, pressure, and time [19]. The degree of recreation period body movement was classified into 0 (absolutely inactive), <500, 999, 1499, and 1500 MET in a week [11].

\section{A. Study Outcome}

The essential examination result quota remained everycause death [11]. Study subject are prosper until the culmination of 2018. Immense fame, date of dying, and cause of loss of life were guaranteed through accomplice the information from the National Death Index using every individual's plain statement code. Partner results including CVDs passing also non-CVDs kicking the mortality [10].

\section{B. Analysis Of Statistics}

Outline insights are accounted for as process \pm specific alteration for analytical elements and as statistic (\%) for unmitigated factors [3]. Constant factors were thought about utilizing the educator Man or t-test Whiteness $U$ test, at the time that proper. Straight out factors were looked at utilizing the $\chi 2$ test. The global tempo of death turned into directed by way of dispensing the degree of dying by the mixture of the following amount and seemed because the fee one thousand individual Every 12 months [9]. Kaplan-Meier endurance bends were built and analysed utilizing the record-vigorous assessment [11]. 
Cox relative risk models were utilized to figure danger proportions (HRs) and 95\% certainty interims (CIs). Multi variable relapse example are built through modification for Sex and age and Age, pay level, local location (urban or non-urban), weight file, pension, debts smooth, dyslexia, renal sickness, smoking, end-arrange renal infection, liver ailment, harm, fasting glucose, serum creation level, and the utilization of headache medicine, stains, and hostile to hypertensive drugs [4].

The communication amongst body action also, CVD was examined in the factual technique. Confined cubic saplings had been tailored with four packs by using treating the volume of bodily improvement as a stable variable utilizing the 'rms' gathering. Influence capability assessments have been completed by using intercourse and version threat subgroups [15]. The gauge cardiovascular danger of subjects without CVD was determined utilizing efficient coronary hazard assessment and a pooled companion condition. Every single factual Exam had been carried out with $\mathrm{R}$ programming adjustment [23].

\section{OUTCOMES - MODEL FEATURES}

The standard attributes of an aggregate of 550681 examination topic are used in Table 1 [20]. The middle stage of the members stayed 56.6 years, $51.6 \%$ stayed man, $40.7 \%$ consumed tension, $14.6 \%$ had diabetes, and $19.9 \%$ stayed present Tabaco. The methods for weight list, circulatory strain, absolute fat, great-thickness lipoprotein fat, small thickness Protein (LDL) cholesterol, and blood pressure had been $\quad 25.2 \mathrm{~kg} / \mathrm{m} 2, \quad 132.6 / 88.7 \mathrm{mmHg}, \quad 200.7 \mathrm{mg} / \mathrm{dL}$, $56.0 \mathrm{mg} / \mathrm{dL}, 129.6 \mathrm{mg} / \mathrm{dL}$, and $110.7 \mathrm{mg} / \mathrm{dL}$, individually [14].

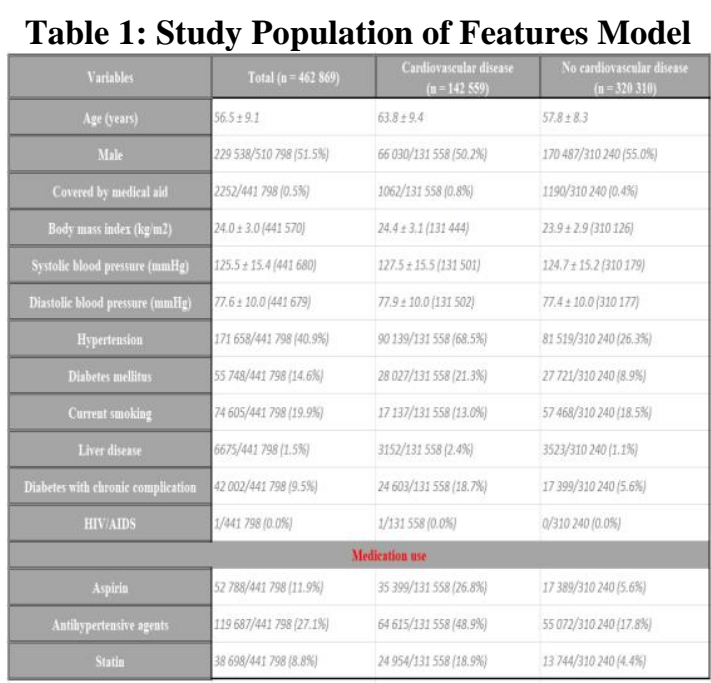

Among the examination populace, $31.7 \%$ of members taken Cardio $(n=142559)$ also anther 71.3\% $(n=320 \quad 310)$ consumed nope past of cardio. Ischemic coronary illness represented the biggest extent of the members with Cardio, trailed by earlier stroke, constant $\mathrm{HF}$, and MI. Cardiovascular illness was related with more seasoned age and a higher predominance of products, for example, hypertension, diabetes, and hyperglycaemia [15]. The extent of members taking cardiovascular meds including headache medicine, hostile to hypertensive specialists, and stains was higher in those with CVD [14].

\section{MONITORING BODY MOMENT}

The scope of body action equal of the examination population remained 1 - 3216 MET-min every 7 days (Additional substantial on the web, Figure 1) 19]. Members through Cardio stayed low body dynamic. Then it had been the ones without Cardio (Table 2 and Additional fabric on the web, Figure 1). The middle body movement equal stayed 540 and 560 MET-min every 7 days in the auxiliary and essential counteraction gatherings, separately [21]. This distinction was factually critical $(\mathrm{P}<0.003)$ in spite of the fact that the impact size was little (Cohen's $d=0.019)$ [24]. The extent of topics that one were absolutely inactive stayed larger in the auxiliary avoidance bunch than in the essential counteraction gathering $(28.1 \%$ and $25.3 \%$, separately, $\mathrm{P}<0.003$ ), while $50.5 \%$ and $51.2 \%$ neglected to accomplish the suggested body movement stage of five hundred METmin every week in all gathering $(\mathrm{P}<0.003)$ [23].

Table 2: Relaxation period body percentage of topics without also with cardio disease.

\begin{tabular}{|c|c|c|c|c|}
\hline Phyical activity & $\operatorname{Tot}(\ln =441788)$ & 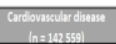 & 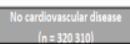 & Rune \\
\hline 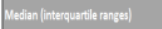 & $560(0.980)$ & $540(0-980)$ & $360(87-980)$ & $\$ .003$ \\
\hline 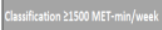 & $8.8 \%(38820)$ & $9.1 \%(11938)$ & $8.77(26882)$ & $\$ .003$ \\
\hline 1000-1699 MET-min/meak & $13.3 \%(58977)$ & $124 \%(16373)$ & $13 \% \%(1260404)$ & \\
\hline S00-999 MER-min/matek & $29.3 \%(129458)$ & $29.0 \%(38091)$ & $29.9 \%(91367)$ & \\
\hline $500 \mathrm{ME}$-min/mank & $23.3 \%(102986)$ & $22.4 \%(29,434)$ & $23 . \%(73552)$ & \\
\hline Totaly ydentary & $253 \%(111557)$ & $28.1 \%(35722)$ & $253 \%$ (75885) & \\
\hline
\end{tabular}

Advantageous material on the web, Table S2 thinks about the distinctions in the standard attributes has indicated by physical action levels. Propelled age, male sex, and a high salary were related with a higher physical action level [3]. Commodities are, for example, diabetes, hypertension, and dyslexia stayed related with a better bodily motion level, whereas current smoking was related with a decrease bodily action degree [9]. The version was equivalent, while the evaluation topics had been stratified through the closeness of CVD (Supplementary material at the net, Tables S4 and S3). Cardiovascular drug usage and adherence were higher among people with greater noteworthy physical action [11]. Among the optionally available counteraction amassing, the nearness of HF become associated with decrease physical motion ranges [15].

The measure of body action of the investigation population expanded through the examination length (Additional physical on the web, Figure 2) [5]. In addition, a noteworthy range of look at topic where modified their measure of body action thru the examination span also turned out to be either increasingly dynamic or less dynamic (Supplementary material on the web, Figure S3). The utilization of prescriptions likewise expanded after some time (Supplementary material on the web, Table S5). While the utilization of stains indicated a surprising increment after some time, the utilization of headache medicine was unaltered [7].

\section{A. Study On Body Action In Death}

The middle follow-up term was nearly 6 years. Figure 1 explains the frequency pace of death per one thousand man period stratified by the nearness of Cardio also the degree of body movement. 
Generally speaking, Cardio was related with an overall extended danger of death (Added physical on the web, Figures 4 and 5) [19]. As additionally appeared in Table 3, they can't satisfy danger of all-reason death demonstrated a J-formed association with the measure of body action [22].

Death hazard was most noteworthy with an absolutely stationary way of life and least with a corporeal action stage of one thousand to one thousand five hundred MET every 7 days paying little heed to CVD [21]. A more significant stage of body action (2011 MET min every 7 days) remained related through a fundamentally advanced danger of death than the channel. Frequency pace of mortality per 1000 man a very long time as indicated by body action equal stratified via cardio malady [10]. Statistics within the make plot display rate quotes consistent with one thousand male every 12 months. Mistake blocks demonstrate 86\% certainty interims [12].

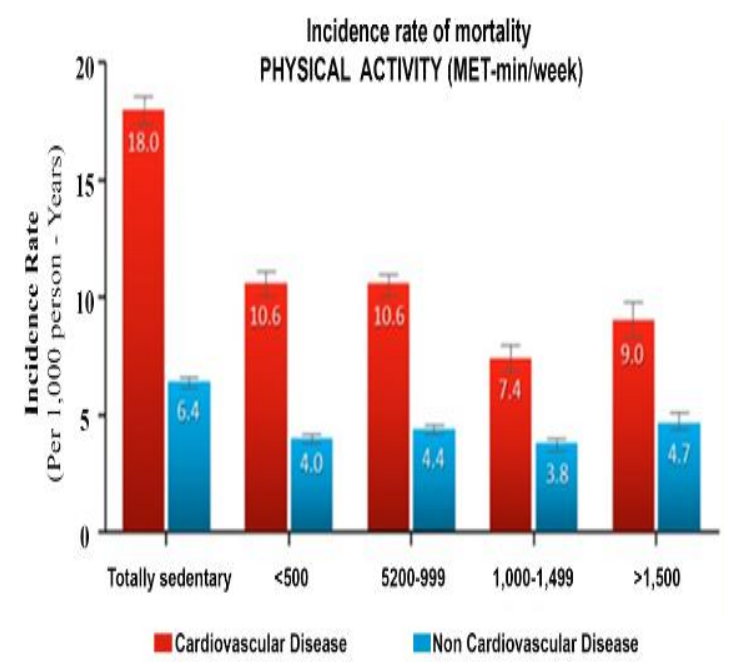

Figure 1 Indicates the incidence rate of mortality in keeping with a thousand person-years stratified by way of the presence of CVD and the level of physical interest.

Up WORD DIRECTION NEED TO CHECK Table 3: Freedom period body action and the danger of death stratified by the nearness of cardio sickness [7]. CI, reality meantime; HR, chance share; MET, mutable image mission. More than one variable-balanced sample are balanced for sex, age, range of salary, local location (non-urban also urban), weight, file, diabetes resonant, hypertension, dyslexia, renal infection, smoker, end-arrange renal sickness, liver ailment, danger, abstaining glucose, creation, ibuprofen, recolor use, and hostile to hypertensive medicine [17]. Figure 2 shows the multi variable-balanced danger of death (tailored key bend is shows in the Take home figure). Then measurable modification, physical movement and mortality displayed a converse connection (Table 3). The distinction in the danger of death between a body movement levels of one thousand five hundred MET min every 7 days and one thousand to one thousand five hundred MET min every 7 days generally vanished. A 500 MET min every 7 days increment in physical movement was related to a $21 \%$ and $6 \%$ chance decrease in death in the auxiliary and essential counteraction gatherings, separately (association $\mathrm{P}<0.003$ ) [13].
Table 3: All Physical Activities Monitoring

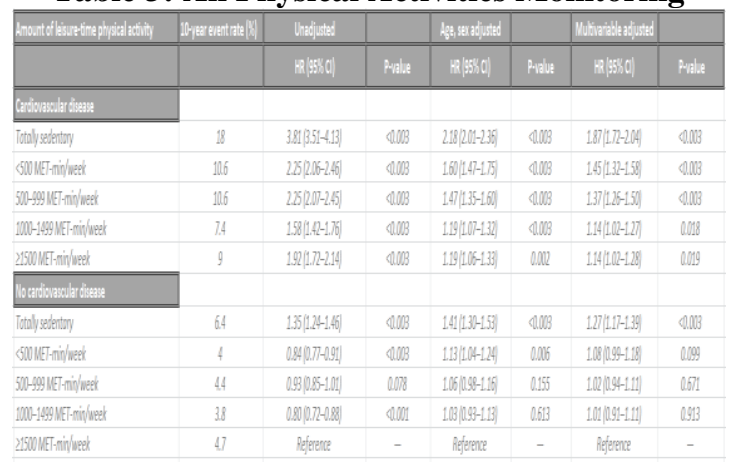

Figure 2: Spreading and composed danger of death as indicated by physical action levels stratified via cardiovascular malady. Cox relapse examination with physical action named an absolute variable: 0 (absolutely stationary), $<500$, to $\geq 1500 \mathrm{MET}$ in a week [3]. The measurable simulations were balanced for sex, age, salary level, weight record, smoking, diabetes mellifluous, hypertension, dyslexia, renal ailment, end-arrange renal malady, liver sickness, any threat, serum, and fasting glucose Creation levels. The blue, blue line and red show risk proportions aimed at topics with and without CVD, separately. Orientation chart demonstrates the quantity of study subjects in every classification [2].

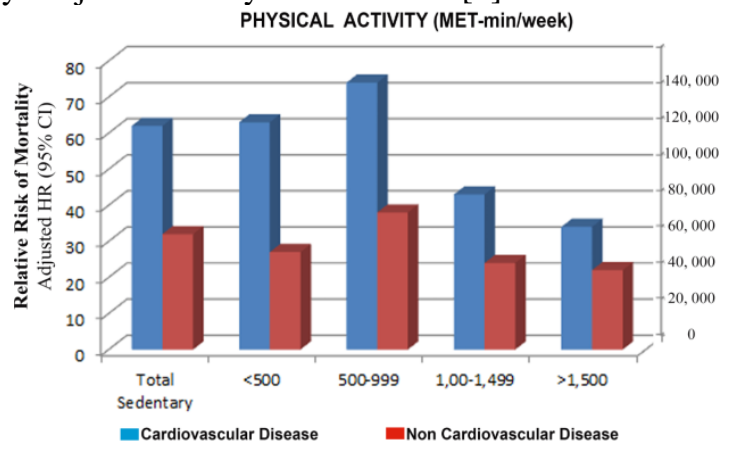

Figure 2: Cardiovascular and Non Cardiovascular

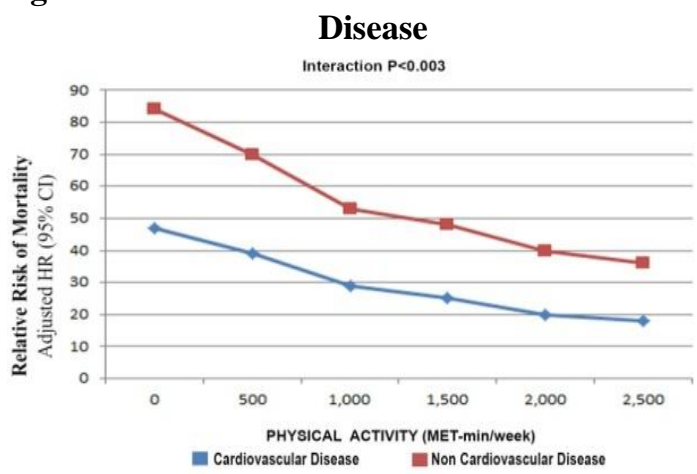

Figure 3: Physical Activity (Relative Risk of Mortility)

Non-traditional connection between physical action and mortality hazard as indicated by the nearness of cardiovascular infection [10]. Confined cubic spline bends were developed concerning physical action preserved equally a persistent adjustment. The blue lines red and shadows show balanced peril proportion and 95\% certainty interims for topics with and without cardio malady, separately [11]. 
The connection among body movement and death indicated various examples between the essential and optional counteraction gatherings [3]. Between the sound topics cannot Cardio [4], the slant stood the sharpest somewhere in the range of 0 and 499 MET in a week, would in general level over 500 MET in a week, and was basically level over $1000 \mathrm{MET}$ in a week [10]. In spite of the fact that the mortality, chance additionally diminished by an advanced body action, equal, and the advantage of expanded physical action was little past 500 MET in a week. Between the members by CVD, the advantage was additionally the best somewhere in the range of 0 and 499 MET in a week. Be that as it may, the portion reaction relationship stretched out past 500 to 1000 MET in a week [5]. The death, danger of members through CVD who achieved bodily movement $\geq 1000 \mathrm{MET}$ in a week (1000 to $\geq 1500 \mathrm{MET}$ in a week) remained fundamentally minor than that in members who remained liberated after CVD yet remained absolutely stationary ( $\mathrm{P}=1.119$ and 1.101 , individually) [7].

Beneficial physical on the web, Tables 6 and 7 appearance the unwanted and balanced danger of heart and non-cardiovascular passing as per the degree of physical movement.

The general example was like that of completely-reason death aside from that CVD was related with an essentially raised danger of cardiovascular demise in spite of a significant equal of body action [2]. The advantage of body movement in the auxiliary avoidance bunch remained firm regardless of the particular sort of CVD (Additional information on the web, Table 8) [8].

Affectability examination found no huge COoperations among the measure of body movement together and sex in the Cardio also in the not at all CVD gatherings (collaboration $\mathrm{P}=1.097$ and 1.124, separately) (Additional physical on the web, Figures 2) [11. Topics deprived of CVD remained additionally isolated by the normal 15 -year danger of lethal CVD (Figure 3) [4]. Although the death chance stayed advanced by expanding estimated cardio hazard, the endurance advantage of body action remained likewise more prominent amongst persons by progressive anticipated cardio hazard. Investigation utilizing shared partner conditions indicated comparative examples (Supplementary material on the web, Figure 3) [16].

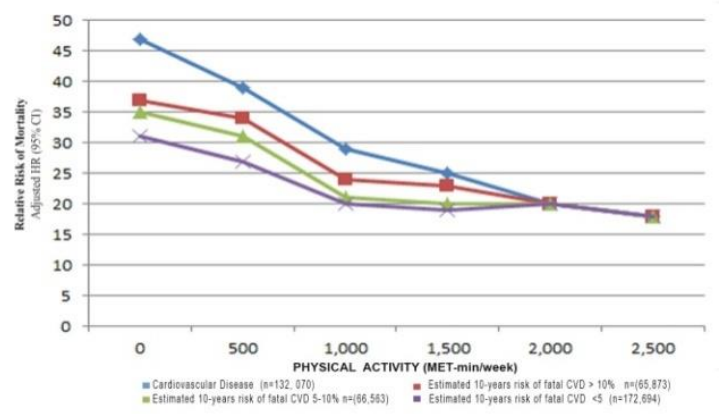

Figure 3: Relative Risk of Mortality

Figure 3: Non-direct connection amongst body movement and death, accidental as indicated by the nearness of cardio sickness and expectable 15-year danger of lethal cardio infection. Limited cubic key bends remained developed as to body action preserved by way of a constant adjustment. Balanced danger proportion and 95\% certainty interims are shown [7]. The orange, blue lines, green, red and shadows demonstrate issues with cardio malady and issues deprived of CVDs ailment who must an expected 15-year danger of deadly cardio illness $\geq 12 \%, 6-12 \%$, and $<6 \%$, individually [8].

\section{LIMITATION}

This examination has a few constraints. Review inclination is 1 of the significant possible impediments. Data detailed on body movement depended on nature-bang polls directed to the well-being registration members. These polls ended-viewed way of life practices during the past 1 week. Furthermore, different sorts of physical action happen during a time for assorted purposes. While just relaxation time physical movement was broken down in this examination [1], occupation, transportation, and family physical exercises likewise add to add up to every day physical action. Third, despite the fact that we performed the thorough measurable change, we can't reject the nearness of balanced perplexing elements [4]. For instance, members With a larger body interest stage may has been decrease malady trouble, improved heart work, and additionally improved cardio respiratory wellness, which have been appearing to anticipate a superior guess. Also, they may have a good way of life practices, for example, a solid eating routine, balance in liquor drinking, and better adherence to prescriptions [18]. Changes in pattern factors after some time, for example, the measure of physical movement, prescription use, and observance to MEDs were not balanced in the examinations. Fourth, a few suppositions stayed completely while ascertaining the measure of body movement [22]. As the surveys concentrated fundamentally on oxygen consuming body movement, data on bonefortifying and muscle-reinforcing practices remained constrained. Be that as it may, the enormous example size in this investigation diminishes the potential vulnerability and predisposition [23]. In conclusion, in light of the fact that the nearness of CVD was resolved utilizing privilege information, here is a probability of orders inclination [21].

\section{CONCLUSION}

This Research, we establish that body movement gives endurance advantages in both in essential and optional CVD avoidance [9]. Although people through prior CVD remained low inclined are bodily dynamic, and their normal profit by physical action stayed more prominent than that of people deprived of CVD. Moreover, the upside of body movement in auxiliary avoidance reached out over 500 to 1000 MET in a week. Sick peoples through CVD ought to be urged to stay away from a stationary way of being also to keep up actually dynamic practices aimed at optional counteraction [11].

\section{REFERENCE}

1. Saperia GM, Yeon SB, Downey B, et al. What's new in cardiovascular medicine? Up To Date. 2020.

2. Stephan S, Tuchman A, Yao S. The Impact of Soda Taxes: PassThrough, Tax Avoidance, and Nutritional Effects. USA: Stanford University Graduate School of Business; 2019. p. 19-21. 
3. United Nations. Transforming our world: the 2030 agenda for sustainable development. 2015. https://www.un.org/ga/search/

4. view_doc.asp?symbol=A/RES/70/1\&Lang=E (accessed July 26, 2019).

5. WHO. Package of essential noncommunicable disease interventions in primary health care. https://www.who.int/ncds/

6. management/pen_tools/en/ (accessed July 26, 2019).

7. United Nations. Transforming our world: the 2030 agenda for sustainable development. 2015. https://www.un.org/ga/search/

8. view_doc.asp?symbol=A/RES/70/1\&Lang=E (accessed July 26, 2019).

9. Du M, Tugendhaft A, Erzse A, et al. Sugar-Sweetened Beverage Taxes: Industry Response and Tactics. Yale J Biol Med. 2018;91(2):185-190.

10. Lancellotti P, Pibarot P, Chambers J, et al. Recommendations for the imaging assessment of prosthetic heart valves: a report from the European Association of Cardiovascular Imaging endorsed by the Chinese Society of Echocardiography, the Inter-American Society of Echocardiography, and the Brazilian Department of Cardiovascular Imaging. European heart journal cardiovascular Imaging. 2016;17(6):589-590

11. Colchero MA, Rivera-Dommarco J, Popkin BM, et al. In Mexico, evidence of sustained consumer response two years after implementing A sugar-sweetened beverage tax. Health Aff (Millwood). 2017;36(3):564- 571.

12. Colchero MA, Rivera-Dommarco J, Popkin BM, et al. In Mexico, evidence of sustained consumer response two years after implementing A sugar-sweetened beverage tax. Health Aff (Millwood). 2017;36(3):564- 571.

13. Xu X, Bishop EE, Kennedy SM, Simpson SA, Pechacek TF. Annual healthcare spending attributable to cigarette smoking: an update. [PDF-157 KB]. Am J Prev Med. 2015;48(3):326-333. http://dx.doi.org/10.1016/j.amepre.2014.10.012. PMID:25498551.

14. National Health and Nutrition Examination Survey (NHANES) data, 1992-2002. Centers for Disease Control and Prevention. http://wwwn.cdc.gov/nchs/nhanes/search/nhanes99_00.aspx. Last accessed: September 24, 2015.

15. Piepoli MF, Hoes AW, Agewall S, et al. 2016 European Guidelines on cardiovascular disease prevention in clinical practice: the sixth Joint Task Force of the European Society of Cardiology and other societies on cardiovascular disease prevention in clinical practice (constituted by representatives of 10 societies and by invited experts). Developed with the special contribution of the European Association for Cardiovascular Prevention and Rehabilitation(EACPR). Eur Heart J 2016; 37: 2315-81.

16. National Health and Nutrition Examination Survey (NHANES) data, 1999-2000. Centers for Disease Control and Prevention. http://wwwn.cdc.gov/nchs/nhanes/search/nhanes99_00.aspx. Las accessed: September 24, 2015.

17. Mozaffarian D, Benjamin EJ, Go AS, et al. Heart Disease and Stroke Statistics-2015 Update: A Report from the American Heart Association. Circulation. 2015;131(4):e29-e322. http://dx.doi.org/10.1161/CIR.0000000000000152.

18. Gunduz S, Ozkan M, Yesin M, et al. Prolonged Infusions of LowDose Thrombolytics in Elderly Patients with Prosthetic Heart Valve Thrombosis. Clinical and applied thrombosis/hemostasis: official journal of the International Academy of Clinical and Applied Thrombosis/ Hemostasis. 2015.

19. Ozkan M, Gunduz S, Gursoy OM, et al. Ultraslow thrombolytic therapy: A novel strategy in the management of PROsthetic MEchanical valve Thrombosis and the prEdictors of outcomE: The Ultra-slow PROMETEE trial. American heart journal. 2015;170(2):409-418.

20. Raff GL, Chinnaiyan KM, Cury RC, Garcia MT, Hecht HS, et al. SCCT guidelines on the use of coronary computed tomographic angiography for patients presenting with acute chest pain to the emergency department: A Report of the Society of Cardiovascular Computed Tomography Guidelines Committee. Journal of Cardiovascular Computed Tomography. 2014;8(4):254 - 271. http://dx.doi.org/10.1016/j.jcct.2014.06.002.

21. Jamal A, Agaku IT, O’Connor E, King BA, Kenemer JB, Neff L; Centers for Disease Control and Prevention. Current cigarette smoking among adults--United States, 2005-2013. MMWR Morb Mortal Wkly Rep. 2014;63(47):1108-1112. PMID:25426653.

22. James PA, Oparil S, Carter BL, et al. 2014 evidence-based guideline for the management of high blood pressure in adults: report from the panel members appointed to the Eighth Joint National Committee (JNC 8). JAMA. 2014;311(5):507-520. http://dx.doi.org/10.1001/jama.2013.284427. PMID:24352797.
23. Stone NJ, Robinson J, Lichtenstein AH, et al. ACC/AHA guideline on the treatment of blood cholesterol to reduce atherosclerotic cardiovascular risk in adults: a report of the American College of Cardiology/American Heart Association Task Force on Practice Guidelines. Circulation. 2014;129(25, suppl 2): S46-48. PMID:24222016.

24. Harikrishnan S, Leeder S, Huffman M, Jeemon P, Prabhakaran D. A Race against Time: The Challenge of Cardiovascular Disease in Developing Economies. 2nd ed. New Delhi, India: New Delhi Centre for Chronic Disease Control; 2014.

25. Institute of Health Metrics and Evaluation. GBD Profile: India. http:// www.healthdata.org/sites/default/files/files/country_profiles/GBD/ih me_

26. gbd_country_report_india.pdf. Accessed April 30, 2014.

27. Fihn SD, Gardin JM, Abrams J, et al; American College of Cardiology Foundation/American Heart Association Task Force. 2012 ACCF/AHA/ACP/AATS/PCNA/SCAI/STS guideline for the diagnosis and management of patients with stable ischemic heart disease: a report of the American College of Cardiology Foundation/American Heart Association task force on practice guidelines, and the American College of Physicians, American Association for Thoracic Surgery, Preventive Cardiovascular Nurses Association, Society for Cardiovascular Angiography and Interventions, and Society of Thoracic Surgeons. Circulation. 2012;126(25):e354-e471.

28. American College of Sports Medicine Position Stand on Physical Activity and Weight Loss, 2011. www.acsm.org/about-acsm/mediaroom/acsm-in-the-news/2011.

\section{AUTHORS PROFILE}

A.Zechariah Jebakumar, Lecturer, Prince Sultan Military College of Health Sciences, Dhahran, Kingdome of Saudi Arabia. Survival Analysis of cardio patients. Email id: zechariah@psmchs.edu.sa.

Dr.R.Ravanan, Joint Director of Collegiate Education, Chennai Region. Survival Analysis of cardio patients. Email id: ravananstat@gmail.com 